\title{
Global incidence of spinal perineural Tarlov's cysts and their morphological characteristics: a meta-analysis of 13,266 subjects
}

\author{
Tomasz Klepinowski $^{1}\left[\right.$ Dojciech Orbik ${ }^{1} \cdot$ Leszek Sagan $^{1}$
}

Received: 12 September 2020 / Accepted: 2 December 2020 / Published online: 16 January 2021

(c) The Author(s) 2021

\begin{abstract}
Background Spinal perineural Tarlov's cysts (TCs) are considered incidental findings that occasionally might exert pressure upon nerve roots and correspond with patients' signs and symptoms. Purpose of this meta-analysis is to deliver global incidence and characteristics (location, size, and shape) of TCs.

Methods Following PRISMA checklist, all major databases were searched by two authors for radiologic studies reporting incidence and morphologic features (location, size, and shape) of TCs. Anatomical Quality Assessment tool was applied for risk of bias evaluation. Meta-analysis of random-effects model was employed. Subgroup analysis for regional distribution, gender, sacral levels, age, correspondence with symptoms, and persistent genital arousal disorder (PGAD) were planned ahead.

Results 22 radiologic studies of level 3 evidence involving 13,266 subjects were included. Global pooled prevalence of TCs was $4.18 \%$ (95\% CI 2.47-6.30). Mean pooled sagittal diameter was $11.86 \mathrm{~mm}$ (95\% CI 10.78-12.93). Sacral cysts strongly prevailed over the other segments. Of the sacral, S2 level was the most common (46.7\% [95\% CI 29.4-60.5]). Geographically, the highest incidence was found in Europe (6.07\% [95\% CI 1.49-13.00]), followed by North America (3.82\% [95\% CI 0.49-9.44]), and Asia (3.33\% [95\% CI 1.52-5.75]). TCs were more common in women than in men (5.84\% vs 3.03\%, $p<0.001$, test of homogeneity, $\chi^{2}$ ). Subjects with PGAD had incidence of $37.87 \%$ (95\% CI $2.45-81.75$ ). TCs in pediatric population are rare- $0.53 \%$ (95\% CI 0.02-1.51). $15.59 \%$ of TCs corresponded with symptoms.

Conclusions Spinal perineural (Tarlov) cysts are found in a minority of population. S2 level of the sacral bone is affected most frequently. There is female predominance. Correspondence with symptoms is seen in less than one-fifth of TCs. Studies with stronger evidence level are needed to corroborate the results. The purported high incidence in PGAD requires confirmation in case-control studies for the risk-ratio calculation.
\end{abstract}

Keywords Tarlov cyst $\cdot$ Spinal perineural cyst $\cdot$ Meta-analysis $\cdot$ Incidence $\cdot$ Sacral cyst $\cdot$ Nerve root cyst

\section{Introduction}

Spinal perineural Tarlov's cysts are thought to be common radiological findings, often incidental and asymptomatic. They are a dilation of the nerve-root sheath and tend to communicate with subarachnoid space through a valve-like

Electronic supplementary material The online version of this article (https://doi.org/10.1007/s00276-020-02644-y) contains supplementary material, which is available to authorized users.

Tomasz Klepinowski

tomasz.klepinowski@pum.edu.pl

1 Department of Neurosurgery, Pomeranian Medical University Hospital No. 1, Szczecin, Poland mechanism, which thus contain cerebrospinal fluid (CSF) as well as neural tissue [3, 6] (Fig. 1). Traditionally, according to Nabor's classification (see Table 1), they are type 2 spinal meningeal cysts, albeit differentiation of these types might often be done only on histological inspection [16]. Incidence varies widely in the literature with reports of as high as $17.7 \%$ and as low as $0.38 \%$ [4, 14, 24]. Also, it has been a subject of controversy which spinal level and nerve root they are most often associated with. Although they are usually linked to the sacral segment of the spine, rarely, they may be seen at other levels, including the cervical and thoracic spine. Despite being mostly asymptomatic, they have been discussed as a potential cause of radiculopathy, persistent genital arousal disorder, as well as a source of CSF leak being a primary culprit of idiopathic intracranial 

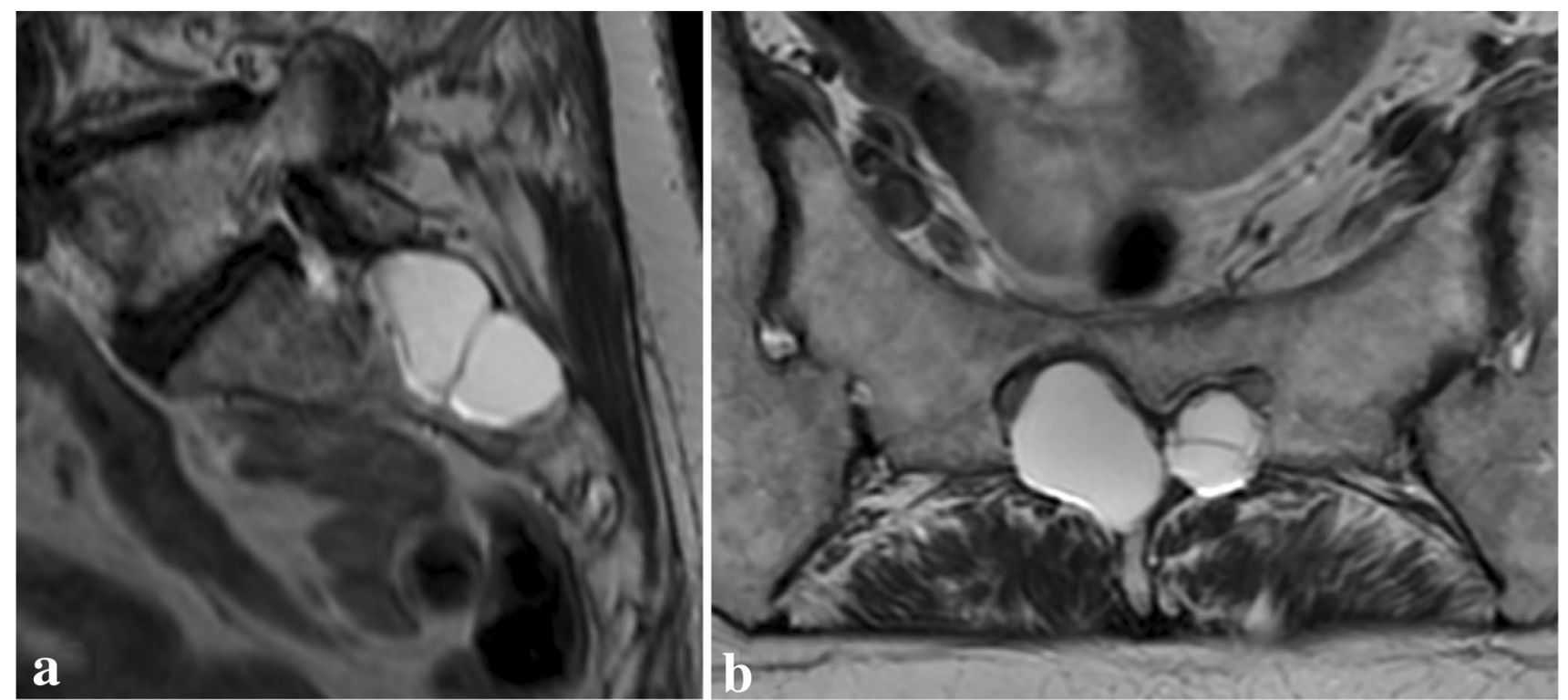

Fig. 1 a Sagittal and $\mathbf{b}$ axial scans of magnetic resonance showing multiple Tarlov cysts at the sacral S2 level causing bone erosion

Table 1 Nabor's classification of spinal meningeal cysts [16]

\begin{tabular}{lc}
\hline Type & Description \\
\hline I & Extradural \\
& cyst without \\
& nerve-root \\
& fibers \\
& Extradural \\
II & cyst with \\
& nerve-root \\
& fibers \\
& Intradural cyst \\
III &
\end{tabular}

hypotension [22]. Authors present the first meta-analysis aiming to discover global incidence and characteristics of Tarlov's cysts.

\section{Methods}

\section{Search strategy}

Major electronic databases (EMBASE, SciELO, China National Knowledge Infrastructure, PubMed MEDLINE, Web of Science) were searched by two researchers (neurosurgical resident TK \& WO) using a MeSH term 'Tarlov cyst' and corresponding synonyms. Full strategy is presented in Electronic Supplementary Material 1. The search started on the 1st August 2020 and was finalized by 6th August 2020. Year of publication was not restricted. Mendeley Desktop 1.19.4 was utilized for title importation, de-duplication, and creation of bibliographic details. Additionally, references of the included papers were checked for pertinent articles. PRISMA checklist is available as Electronic Supplementary Material 2.

\section{Eligibility}

Analysis was limited to those studies that met our inclusion criteria: (1) clear incidence of Tarlov's cysts among a specified group of subjects; (2) the incidence regarded the group of at least 10 subjects. Papers were excluded if any criterion of the following was found: (1) conference abstracts, (2) commentaries, (3) letters to the Editors, (4) insufficient data, (5) incidence of Tarlov's cysts was aggregated with other lesions and could not be disaggregated, (6) case reports, and (7) series with less than 10 subjects among whom presence of the cysts was evaluated. TK and WO are fluent in English and Polish. In case of other language, professional translators were inquired.

\section{Data extraction}

Data were extracted by two of us (TK and WO). The following characteristics were of interest: (1) total number of subjects evaluated for presence of Tarlov's cysts, (2) number of individuals with at least one TC, (3) number of individuals with multiple TCs, (4) total number of TCs in the group, (5) number of patients with only one, only two, only three (and so on) TCs, respectively, (6) number of TCs in sacral, lumbar, thoracic, or cervical region, respectively, (7) number of TCs corresponding with symptoms (excluding back pain) or signs, (8) number of TCs not corresponding with symptoms or signs, (9) number of TCs in patients with persistent genital arousal disorder, (10) number of TCs in patients 
with transitional lumbosacral vertebra, (11) mean age of the group with TCs, (12) number of adults and children with TCs, (13) size of TCs in millimeters (the maximal axial diameter), (14) prevalence of TCs with respect to nerve-root level, (15) prevalence with regard to sex, (16) shape of TCs, (17) region of origin, and (18) modality of imaging. Data were collected only if it could have been disaggregated. In several cases, the disaggregated data were provided by the corresponding authors who were communicated with.

\section{Quality and risk of bias assessment}

Two researchers are TK and WO. Risk of bias was assessed in two ways: quantitatively and qualitatively. Qualitative analysis was performed by means of AQUA tool (Anatomical Quality Assessment) [8] independently by two reviewers. In case of disagreement, a senior neurosurgeon (LS) was reached for consensus. AQUA tool appreciates quality of the study in five domains: (1) objectives and subject characterization, (2) study design, (3) methodology, (4) descriptive anatomy, and (5) reporting results. Each domain asks a series of binary signaling questions. If a single signaling question within a domain was answered 'No', then consensus was reached whether the entire domain should be 'High risk' or 'Low risk'. On the other hand, in case of two or more signaling questions being answered 'No', then the domain was instantly marked as constituting a 'High risk'. On the other hand, quantitative analysis of the risk of bias was conducted by delineating a mathematically grounded funnel plot and evaluating its symmetry.

\section{Statistics}

Formal statistical estimation of pooled prevalence was executed using software MetaXL 5.3, EpiGear International Pty Ltd. (Brisbane, Australia). Estimation of mean sagittal diameter was executed with Comprehensive Meta-Analysis V3 (Englewood, New Jersey, USA). For single-categorical variables, pooled prevalence was estimated with corresponding confidence intervals of $95 \% . I^{2}$ and $\chi^{2}$ were incorporated into evaluation of heterogeneity. $I^{2}$ value was interpreted with classic approach: 0-40\%: not be important, 30-60\% moderate heterogeneity, 50-90\%: substantial heterogeneity, and 75-100\%: considerable heterogeneity. Arbitrary $p$ value of $<10 \%$ was set for Cochrane $Q$ significance $(<0.10)$. Conversely, significance of comparative tests was agreed to standard $<5 \%(<0.05)$. Random-effects model for metaanalysis of pooled prevalence was applied. Subgroup differences in prevalence were compared using test of homogeneity based on $\chi^{2}$ (Statistica 13.3.0, TIBCO Software Inc, Palo Alto, USA).

\section{Subgroup analysis}

Subgroup analysis was planned with regard to geographical regions, specific entities such as persistent genital arousal disorder, sex, and age (children and adults). Distribution within the sacral spine was also analyzed to determine which sacral level is affected most commonly.

\section{Results}

\section{Selection process}

Initial search yielded 4762 records including 2 from references of the pertinent articles. Following the de-duplication, 3518 titles and abstracts were checked for relevance to the topic. 41 full-text articles were assessed for eligibility (Fig. 2). In total, 22 papers were included in meta-analysis [2, 4, 5, 9-15, 17-21, 23-29]: 19 for estimation of the general incidence as well as for subgroup analysis, whereas three articles were included solely in subgroup analysis without involving them in the general pool, because they pertained specifically to small groups of patients with symptoms of PGAD, two of them presented unusually high incidence of TC, and hence were deemed to pose a risk of bias for the general pool.

\section{Risk of bias and quality}

Tabular display of AQUA tool summary is presented in Table 2. The highest risk was related with methodology, whereas the lowest risk was attributed to study design and reporting results. The funnel plot is presented in Fig. 3 .

\section{Characteristics of the included studies}

Characteristics are presented in Table 3. In total, 13,266 subjects were included into the meta-analysis. 21 studies sought Tarlov's cysts in MRI scans, whereas one study evaluated only myelograms. No study with evidence stronger than level 3 was identified. Time frame of the studies spanned from 1980 to 2020. Age was known in 14 studies $(n=6717)$. Thus, mean age of those in the main cohort was 48.9 years. Geographical distribution was as follows: 8 studies from North America $(n=1298), 6$ from Europe $(n=5903), 7$ from Asia $(n=5808), 1$ from Africa $(n=217)$, and neither from Australia nor South America.

\section{Pooled estimates and subgroup analysis}

Random-effects model estimated global pooled prevalence of Tarlov's cysts to be $4.18 \%$ (95\% CI 2.47-6.30, $Q=461.49, p<0.01, I^{2}=96.1 \%$; see Fig. 4). Considering 


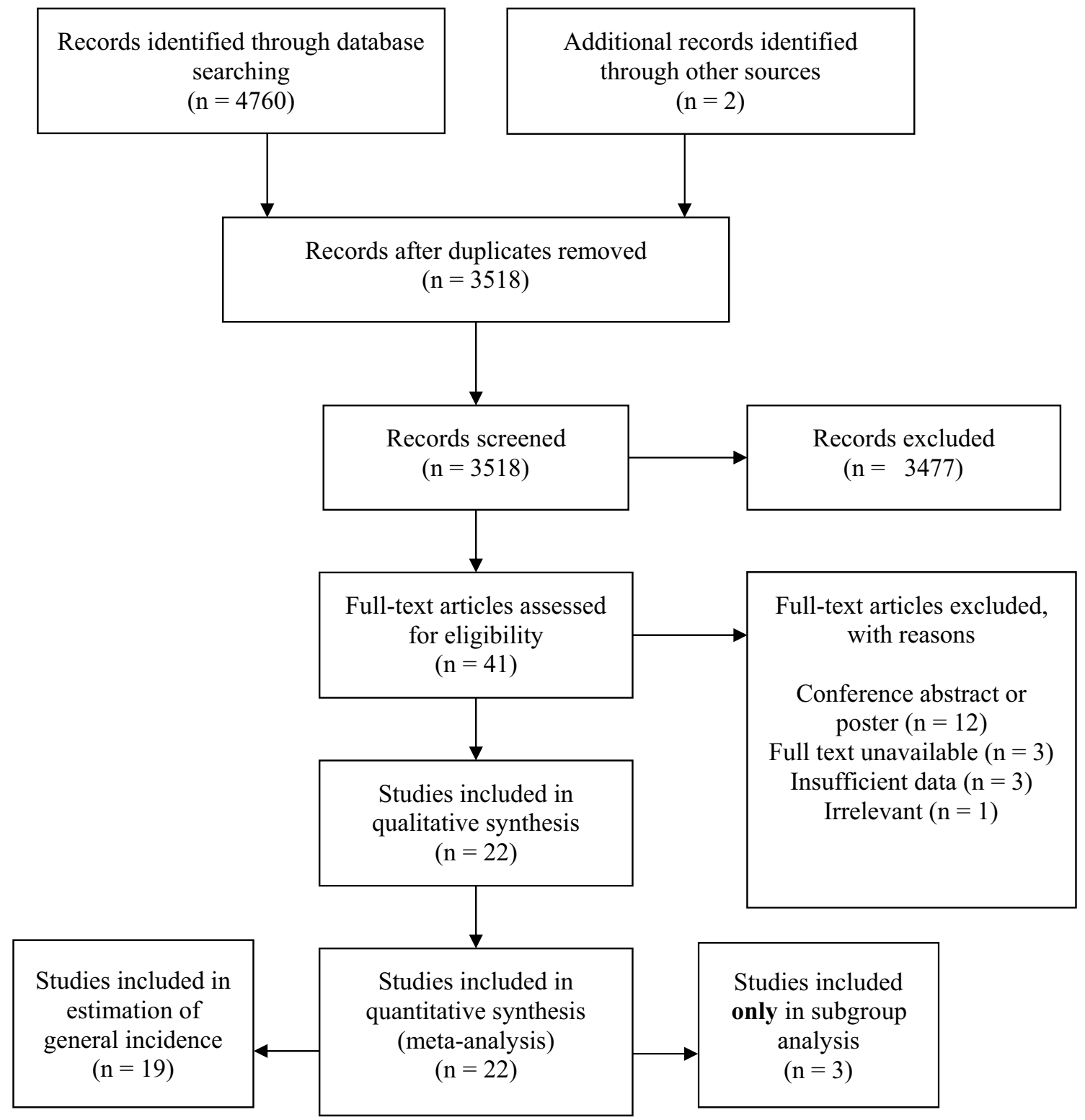

Fig. 2 Process of study selection

geographical distribution, the highest incidence of TCs was noted in Europe (6.07\% [95\% CI 1.49-13.00], $Q=269.62, p<0.001, I^{2}=98.15 \%$ ), followed by North America $(3.82 \%$ [95\% CI 0.49-9.44], $Q=65.62$, $\left.p<0.001, I^{2}=92.4 \%\right)$, Asia (3.33\% [95\% CI 1.52-5.75], $\left.Q=89.32, I^{2}=93.28 \%, p<0.001\right)$, and Africa $(0.67 \%$ [95\% CI 0.00-1.97]; a single study, Cochran's $Q$ was not calculated). Comparing all four regions, the geographical differences were not significant ( $p=0.213$; test of homogeneity, Chi squared). However, direct comparison revealed that incidence in Europe was significantly higher than in Asia $(p<0.01)$ or in North America $(p<0.01)$. Incidence in Asia was not dissimilar from that in North America $(p=0.607)$. Subjects with persistent genital arousal disorder showed prevalence of $37.87 \%$ (95\% CI $2.45-81.75 ; Q=14.33, I^{2}=86.0 \%$ ). Size of the cysts was measured in three studies $(n=1960)$. Mean pooled diameter was $11.86 \mathrm{~mm}(95 \%$ CI 10.78-12.93, variance $=0.302$, $Z$ value $\left.=21.59, p<0.01, I^{2}=83.5 \%\right)$. Incidence in women was $7.01 \%$ (95\% CI $2.57-13.21, Q=221.07, p<0.01$, $I^{2}=96.38 \%$ ), whereas in men $4.05 \%$ (95\% CI $1.07-8.57$, $\left.Q=27.86, p<0.01, I^{2}=89.23 \%\right)$. Tarlov's cysts in pediatrics were rare $(0.53 \%$ [95\% CI $0.02-1.51, Q=1.61$, $\left.\left.p=0.448, I^{2}=0 \%\right]\right)$. Shape was oval/rounded in $58.3 \%$ of TCs and tubular in $41.7 \%\left(Q=30.13, p<0.01, I^{2}=96.7 \%\right)$. Of the cysts that were found, $57.4 \%$ were single, whereas in $42.6 \%$, multiple TCs were seen $(Q=30.21, p<0.01$, $I^{2}=76.8$ ). Only $15.59 \%$ of TCs corresponded with 
Table 2 Summary of risk of bias evaluation by means of an Anatomical Quality Assessment (AQUA) tool

\begin{tabular}{|c|c|c|c|c|c|}
\hline \multirow[t]{2}{*}{ References } & \multicolumn{5}{|l|}{ Risk of Bias } \\
\hline & $\begin{array}{l}\text { Objectives and } \\
\text { study character- } \\
\text { istics }\end{array}$ & Study design & Methodology & $\begin{array}{l}\text { Descriptive } \\
\text { anatomy }\end{array}$ & $\begin{array}{l}\text { Reporting } \\
\text { of results }\end{array}$ \\
\hline Burdan et al. [2] & Low & Low & Low & Low & High \\
\hline Gleeson et al. [4] & Low & Low & Low & High & Low \\
\hline Gopalakrishnan et al. [5] & High & Low & High & High & Low \\
\hline Jeong et al. [9] & Low & Low & Low & High & Low \\
\hline Joo et al. [10] & Low & Low & High & High & Low \\
\hline Komisaruk and Lee [11] & High & High & High & Low & Low \\
\hline Kuhn et al. [12] & Low & Low & High & Low & Low \\
\hline Langdown et al. [13] & Low & Low & High & Low & Low \\
\hline Larsen et al. [14] & High & High & High & Low & Low \\
\hline Lim et al. [15] & Low & Low & High & Low & Low \\
\hline Oaklander et al. [17] & High & High & High & High & High \\
\hline Park et al. [18] & Low & Low & Low & Low & Low \\
\hline Paulsen et al. [19] & High & Low & High & High & High \\
\hline Petrasic et al. [20] & Low & Low & High & High & Low \\
\hline Pink et al. [21] & High & High & High & High & High \\
\hline Ramadorai et al. [23] & Low & Low & High & High & Low \\
\hline Ramirez et al. [24] & Low & High & High & High & Low \\
\hline Senoglu et al. [25] & Low & Low & High & Low & Low \\
\hline Shi et al. [26] & High & Low & High & High & Low \\
\hline Tani et al. [27] & Low & Low & High & High & Low \\
\hline Zacharakis et al. [28] & Low & Low & High & High & Low \\
\hline Zeitoun et al. [29] & Low & Low & High & High & Low \\
\hline
\end{tabular}

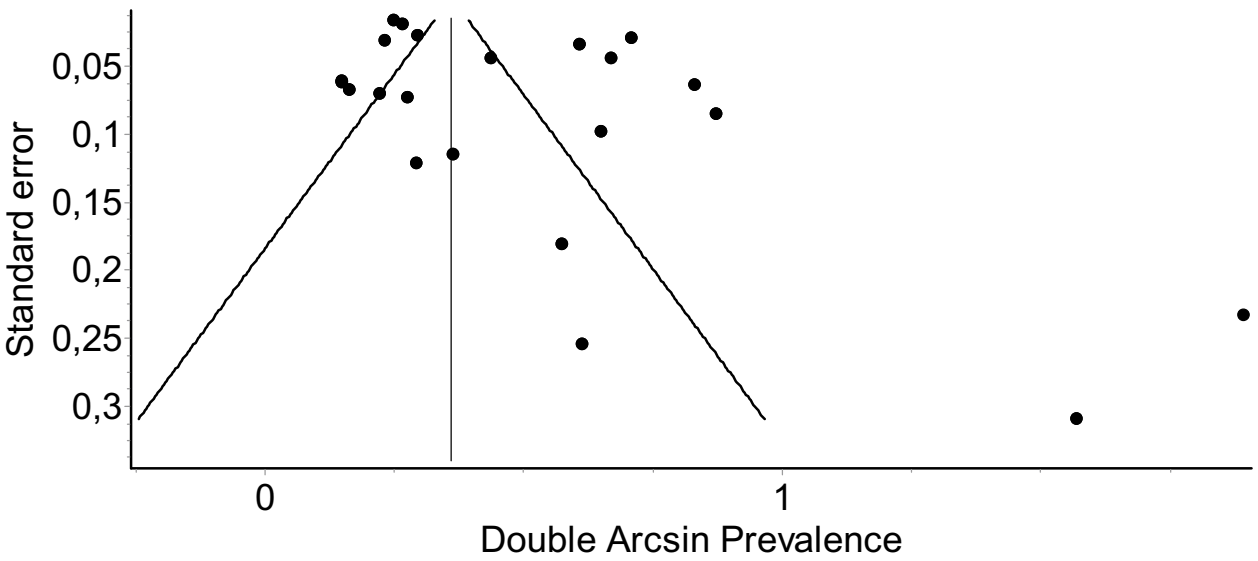

Double Arcsin Prevalence
Fig. 3 Funnel plot quantitatively illustrating the risk of bias of Tarlov cyst prevalence in the general pool

symptoms of neural compromise (radiculopathy, chronic cauda equina syndrome, myelopathy, PGAD, or the like) (see Table 4). 
Table 3 Characteristics of the studies

\begin{tabular}{lllrc}
\hline References & Global region & Imaging & Subjects & $\begin{array}{c}\text { Tarlov cyst } \\
\text { incidence (\%) }\end{array}$ \\
& & & & 8.91 \\
Burdan et al. [2] & Europe & MRI & 260 & 0.38 \\
Gleeson et al. [4] & Europe & MRI & 200 & 1.00 \\
Gopalakrishnan et al. [5] & Asia & MRI & 494 & 10.73 \\
Jeong et al. [9] & Asia & MRI & 2669 & 1.72 \\
Joo et al. [10] & Asia & MRI & 18 & 66.67 \\
Komisaruk and Lee [11]* & North America & MRI & 1100 & 12.00 \\
Kuhn et al. [12] & Europe & MRI & 3535 & 1.53 \\
Langdown et al. [13] & Europe & MRI & 136 & 17.65 \\
Larsen et al. [14] & Europe & Myelography & 242 & 16.12 \\
Lim et al. [15] & North America & MRI & 10 & 50.00 \\
Oaklander et al. [17]* & North America & MRI & 1268 & 2.13 \\
Park et al. [18] & Asia & MRI & 500 & 4.60 \\
Paulsen et al. [19] & North America & MRI & 185 & 1.62 \\
Petrasic et al. [20] & North America & MRI & 15 & 6.67 \\
Pink et al. [21]* & North America & MRI & 67 & 1.49 \\
Ramadorai et al. [23] & North America & MRI & 261 & 0.38 \\
Ramirez et al. [24] & North America & MRI & 1000 & 1.30 \\
Senoglu et al. [25] & Asia & MRI & 75 & 2.67 \\
Shi et al. [26] & Asia & MRI & 102 & 9.80 \\
Tani et al. [27] & Asia & MRI & 30 & 6.67 \\
Zacharakis et al. [28] & Europe & MRI & 217 & 0.46 \\
Zeitoun et al. [29] & Asia & MRI & &
\end{tabular}

Excluded from estimation of the general pooled prevalence, included only in subgroup analysis

*Patients with persistent genital arousal disorder

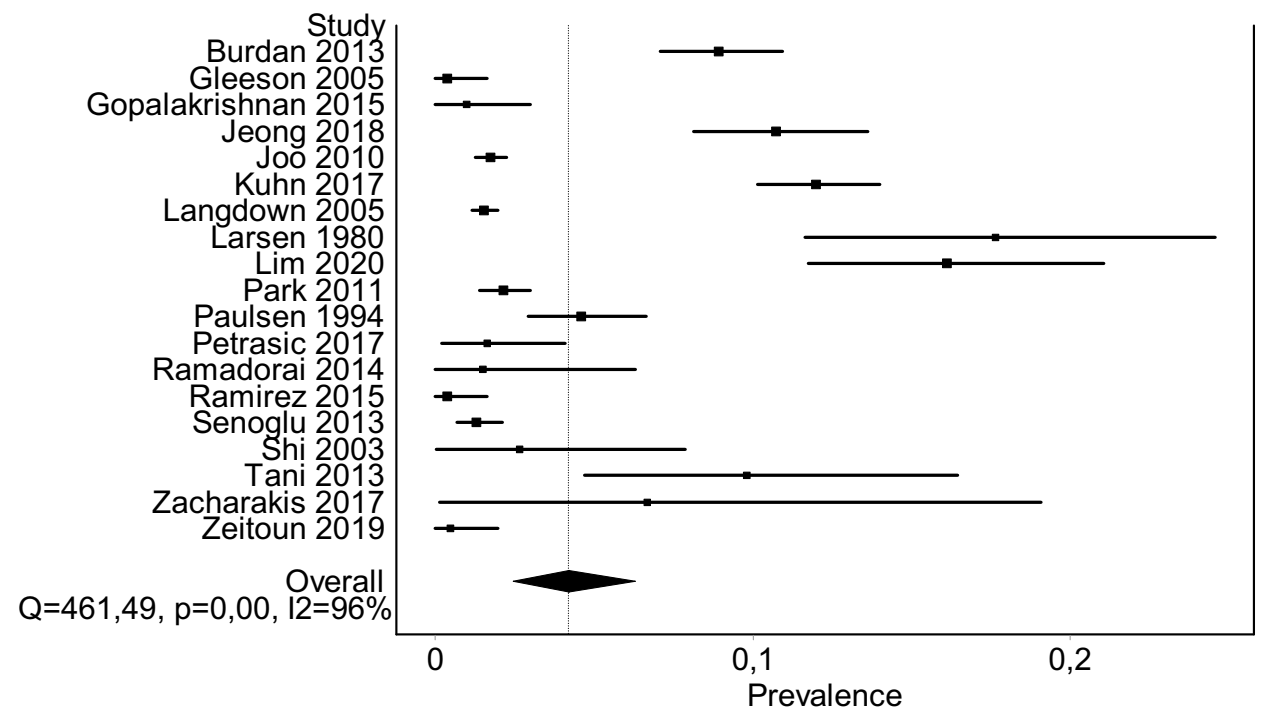

\begin{tabular}{|c|c|}
\hline 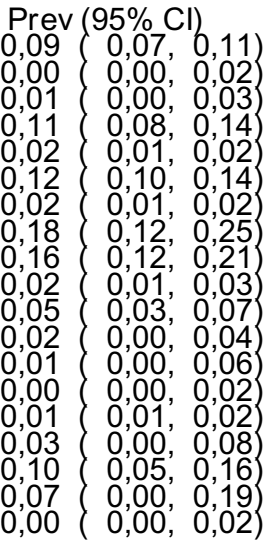 & \\
\hline$(0,02,0,06)$ & \\
\hline
\end{tabular}

Fig. 4 A forest plot depicting global pooled prevalence of Tarlov cysts. Overall prevalence was estimated at 4.18\% (95\% CI 2.47-6.30) 
Table 4 Subgroup analysis of Tarlov cyst prevalence

\begin{tabular}{|c|c|c|c|c|}
\hline Subgroup & $\begin{array}{l}\text { Number of } \\
\text { studies (sub- } \\
\text { jects) }\end{array}$ & Pooled prevalence $(95 \% \mathrm{CI})$ & $\begin{array}{l}I^{2} \text { het- } \\
\text { erogeneity } \\
(\%)\end{array}$ & $\begin{array}{l}p \text { value of } \\
\text { Cochran } Q\end{array}$ \\
\hline \multicolumn{5}{|l|}{ Age group } \\
\hline Adults & 13 (11965) & $5.51 \%(3.11-8.53)$ & 97.1 & $<0.001$ \\
\hline Pediatrics & $3(428)$ & $0.53 \%(0.02-1.51)$ & 0 & 0.448 \\
\hline Persistent genital arousal disorder & $3(43)$ & $37.87 \%(2.45-81.75)$ & 86.0 & 0.001 \\
\hline Sacral levels* & $9(4274)$ & & 85.7 & $<0.001$ \\
\hline $\mathrm{S} 1$ & & $21.7 \%(9.3-35.0)$ & & \\
\hline $\mathrm{S} 2$ & & $46.7 \%(29.4-60.5)$ & & \\
\hline $\mathrm{S} 3$ & & $26.4 \%(12.8-40.2)$ & & \\
\hline $\mathrm{S} 4$ & & $5.2 \%(0.0-12.9)$ & & \\
\hline Gender & $9(4333)$ & & & \\
\hline Women & $9(3103)$ & $7.01 \%(2.57-13.21)$ & 96.4 & $<0.001$ \\
\hline Men & $4(1230)$ & $4.05 \%(1.07-8.57)$ & 91.75 & $<0.001$ \\
\hline \multicolumn{5}{|l|}{ Geographical distribution } \\
\hline North America & $8(1298)$ & $3.82 \%(0.49-9.44)$ & 92.4 & $<0.001$ \\
\hline Europe & $6(5903)$ & $6.07 \%(1.49-13.00)$ & 98.15 & $<0.001$ \\
\hline Asia & $7(5808)$ & $3.33 \%(1.52-5.75)$ & 93.3 & $<0.001$ \\
\hline Africa & $1(217)$ & $0.67 \%(0.00-1.97)$ & 0 & - \\
\hline Shape of TCs & $2(1236)$ & & 96.7 & $<0.001$ \\
\hline oval/rounded & & $58.3 \%(8-100)$ & & \\
\hline Tubular & & $41.7 \%(0-92)$ & & \\
\hline Patients with & $8(1893)$ & & 76.8 & $<0.001$ \\
\hline Only one TC & & $57.4 \%(34.9-78.5)$ & & \\
\hline Multiple TCs & & $42.6 \%(21.5-65.1)$ & & \\
\hline TCs corresponding with symptoms & $8(2633)$ & $15.59 \%(2.47-35.24)$ & 77.9 & $<0.001$ \\
\hline
\end{tabular}

\section{Discussion}

Although in literature a varyingly wide range of incidence of TCs is reported, the present meta-analysis shows that mean global pooled prevalence is $4.27 \%$ and the confidence interval is relatively narrow (95\% CI 2.56-6.38). The highest general incidence-17.65\% — was suggested by Larsen et al. in 1980 [14]. As contributory and impactful their research might have been, it was the oldest of the included studies and also the only one that took advantage of myelography. All the other papers were from the new millennium and evaluated cysts using magnetic resonance imaging. This crucial methodological difference might partially explain the discrepancy.

8 studies addressed gender-specific prevalence. In women, TCs occurred at $7.01 \%$ (95\% CI 2.57-13.21) whereas men had prevalence of $4.05 \%$ (95\% CI 1.07-8.57). Apparently, females are more often affected by TCs $\left(p=0.0003\right.$, test of homogeneity, $\left.\chi^{2}\right)$. Literature has not explored the causes of this sex-related predominance, yet. Our hypothesis is that formation of TCs in adult females might be associated with the level of primary female sex hormones, since in pediatrics, when these hormones are usually low, TCs are an exceptional finding [12]. This hypothesis might be corroborated in future by conducting case-control research studies comparing a group of hypogonadism with healthy controls.

\section{Correspondence with symptoms}

This meta-analysis shows that only about $15.59 \%$ of TCs are symptomatic. This is somewhat close to what has been suggested in the past by Paulsen et al. who indicated that approximately only 1 in 5 TCs might produce clinically significant symptoms [19]. Clinical picture that may truly be related to the presence of TCs stems from neural compromise and most commonly consists of radicular pain in the relevant dermatomal distribution or motor weakness, rarely myelopathy if a TC is located above the conus medullaris $[7,13,19]$. Persistent genital arousal disorder is under debate as an entity that could be linked with TCs [11]. Nonspecific back pain was not attributed to TCs in the present meta-analysis. 


\section{Sacral segments}

Sacral perineural cysts were the ones to be documented most consistently. It was a subject of controversy which sacral level is usually involved. Incidence of S2 TCs was declared highest in three studies $[2,9,15]$. S3 was the most prevalent in two papers, whereas $S 1$ in one $[12,14,25]$. Pooling the data revealed that, in fact, $\mathrm{S} 2$ level is the one to be disturbed most frequently (46.7\% [95\% CI 29.4-60.5], $Q=49.12$, $\left.I^{2}=85.7 \%, p<0.001\right)$.

\section{Tarlov cysts and persistent genital arousal disorder}

Subgroup analysis reveals that patients with PGAD, mostly women, might be more prone to developing TCs. Two of three studies involving those patients gave an account of high TC incidence (50-66.67\%) [1, 17]. However, one study stated to the contrary $(6.67 \%)$, indicating that the previously mentioned studies might have been biased [21]. Pooled prevalence for the time being is $37.87 \%$ Currently, more studies of larger samples, optimally of case-control design, would be appreciated to dispel doubts.

\section{Implications, limitations, and future directions}

Despite being comprehensive, this meta-analysis is not free from limitations. High methodological bias found in many papers is highlighted, primarily due to the fact that in many of them, measures were not taken to reduce intra-/interobserver variability. Small number of studies about PGAD is the reason of the wide confidence interval of incidence in this group. It, however, indicates that PGAD might be associated with TCs. Therefore, case-control studies would be of value for calculation of the risk ratio. Based on the findings of this study, it is suggested that more studies on incidence of TCs be conducted in South America, Africa, and Australia. Moreover, results of this meta-analysis and the emphasized gaps in knowledge can be used in future research on Tarlov's cysts. As all but one of the studies assessed only lumbosacral spine MRI and not whole-spine MRI, there exists some risk of bias regarding counting the vertebrae in individuals with transitional abnormalities. Since only a handful of papers delineated morphological features of the cysts such as size or shape, as for now, it is difficult to seek link between these characteristics and clinical picture. Especially, it is still problematic to determine quantitative relation between TCs and the most frequent complaints expressed by patients, which is radicular pain and local back pain. Moreover, there are not enough data to univocally answer the question whether spinal cord or cauda equina might herniate into the TCs. Hence, more precise depiction is encouraged in upcoming studies.

\section{Conclusion}

Spinal perineural Tarlov's cysts are found in a minority of population. Women tend to develop TCs more often than men. Perineural cysts in pediatrics seem to be rare findings. Incidence in Europe appears to be higher than in other continents. S2 level of the sacral bone is affected most frequently. Possibly high incidence in PGAD requires confirmation in case-control studies for the risk-ratio calculation. Studies with evidence stronger than level 3 are needed to corroborate the results of this meta-analysis.

Acknowledgements TK would like to acknowledge authors of the included studies, who contributed to this meta-analysis with their credible effort to provide the detailed data.

Author contributions TK: conceptualization, methodology, validation, formal analysis, investigation, resources, data curation, writingoriginal draft, writing - review and editing, visualization, and project administration. WO: investigation and data curation. LS: writingreview and editing, supervision, and project administration.

Funding Open access funding provided by Pomeranian Medical University in Szczecin.

\section{Compliance with ethical standards}

Conflict of interest On behalf of all authors, the corresponding author states that there is no conflict of interest.

Consent to participate As this was a retrospective analysis of the studies that had been published in the past, no consent to participate was necessary.

Consent for publication (include appropriate statements) Authors of this study grant the publisher sole and exclusive license of the full copyright.

Open Access This article is licensed under a Creative Commons Attribution 4.0 International License, which permits use, sharing, adaptation, distribution and reproduction in any medium or format, as long as you give appropriate credit to the original author(s) and the source, provide a link to the Creative Commons licence, and indicate if changes were made. The images or other third party material in this article are included in the article's Creative Commons licence, unless indicated otherwise in a credit line to the material. If material is not included in the article's Creative Commons licence and your intended use is not permitted by statutory regulation or exceeds the permitted use, you will need to obtain permission directly from the copyright holder. To view a copy of this licence, visit http://creativecommons.org/licenses/by/4.0/.

\section{References}

1. Biewenga E, Goldstein S, Trofimenko V et al (2019) 175 the lumbosacral spine, a source for unusual pelvic and penile pain in men. J Sex Med 16:S88. https://doi.org/10.1016/j. jsxm.2019.01.184 
2. Burdan F, Mocarska A, Janczarek M et al (2013) Incidence of Spinal Perineurial (Tarlov) cysts among east-European patients. PLoS ONE. https://doi.org/10.1371/journal.pone.0071514

3. Fletcher-Sandersjöö A, Mirza S, Burström G et al (2019) Management of perineural (Tarlov) cysts: a population-based cohort study and algorithm for the selection of surgical candidates. Acta Neurochir (Wien) 161:1909-1915. https://doi.org/10.1007/s0070 1-019-04000-5

4. Gleeson TG, O'Connell MJ, Duke D et al (2005) Coronal oblique turbo STIR imaging of the sacrum and sacroiliac joints at routine MR imaging of the lumbar spine. Emerg Radiol 12:38-43. https ://doi.org/10.1007/s10140-005-0440-1

5. Gopalakrishnan N, Nadhamuni K, Karthikeyan T (2015) Categorization of pathology causing low back pain using magnetic resonance imaging (MRI). J Clin Diagn Res 9:TC17-TC20. https ://doi.org/10.7860/JCDR/2015/10951.5470

6. Greenberg MS (2019) Special conditions affecting the spinal cord. In: Greenberg MS (ed) Handbook of Neurosurgery, 9th edn. Thieme, New York, pp 1202-1205

7. Henderson FC, Austin C, Benzel E et al (2017) Neurological and spinal manifestations of the Ehlers-Danlos syndromes. Am J Med Genet Part C Semin Med Genet 175:195-211. https://doi. org/10.1002/ajmg.c.31549

8. Henry BM, Tomaszewski KA, Ramakrishnan PK et al (2017) Development of the anatomical quality assessment (AQUA) tool for the quality assessment of anatomical studies included in metaanalyses and systematic reviews. Clin Anat 30:6-13

9. Jeong YM, Jeon JY, Lee S-W et al (2018) The termination level of the dural sac relevant to caudal epidural block in lumbosacral transitional vertebrae: a comparison between sacralization and lumbarization groups. Pain Phys 21:73-81

10. Joo J, Kim J, Lee J (2010) The prevalence of anatomical variations that can cause inadvertent dural puncture when performing caudal block in Koreans: a study using magnetic resonance imaging. Anaesthesia 65:23-26. https://doi.org/10.111 1/j.1365-2044.2009.06168.x

11. Komisaruk BR, Lee HJ (2012) Prevalence of Sacral Spinal (Tarlov) cysts in persistent genital arousal disorder. J Sex Med 9:20472056. https://doi.org/10.1111/j.1743-6109.2012.02765.x

12. Kuhn FP, Hammoud S, Lefèvre-Colau MM et al (2017) Prevalence of simple and complex sacral perineural Tarlov cysts in a French cohort of adults and children. J Neuroradiol 44:38-43. https://doi.org/10.1016/j.neurad.2016.09.006

13. Langdown AJ, Grundy JRB, Birch NC (2005) The clinical relevance of Tarlov cysts. J Spinal Disord Tech 18:29-33. https:// doi.org/10.1097/01.bsd.0000133495.78245.71

14. Larsen JL, Smith D, Fossan G (1980) Arachnoidal diverticula and cystlike dilatations of the nerve-root sheaths in lumbar myelography. Acta Radiol Ser Diagn 21:141-145. https://doi. org/10.1177/028418518002102A02

15. Lim VM, Khanna R, Kalinkin O et al (2020) Evaluating the discordant relationship between Tarlov cysts and symptoms of pudendal neuralgia. Am J Obstet Gynecol 222:70.e1-70.e6. https ://doi.org/10.1016/j.ajog.2019.07.021

16. Nabors MW, Pait TG, Byrd EB et al (1988) Updated assessment and current classification of spinal meningeal cysts. J Neurosurg 68:366-377. https://doi.org/10.3171/jns.1988.68.3.0366
17. Oaklander AL, Sharma S, Kessler K, Price BH (2020) Persistent genital arousal disorder. Pain Rep 5:e801. https://doi.org/10.1097/ pr9.0000000000000801

18. Park HJ, Jeon YH, Rho MH et al (2011) Incidental findings of the lumbar spine at MRI during herniated intervertebral disk disease evaluation. Am J Roentgenol 196:1151-1155. https://doi. org/10.2214/AJR.10.5457

19. Paulsen RD, Call GA, Murtagh FR (1994) Prevalence and percutaneous drainage of cysts of the sacral nerve root sheath (Tarlov cysts). Am J Neuroradiol 15:293-297

20. Petrasic JR, Chhabra A, Scott KM (2017) Impact of MR neurography in patients with chronic cauda equina syndrome presenting as chronic pelvic pain and dysfunction. Am J Neuroradiol 38:418-422. https://doi.org/10.3174/ajnr.A4994

21. Pink L, Rancourt V, Gordon A (2014) Persistent Genital Arousal in Women With Pelvic and Genital Pain. J Obstet Gynaecol Canada 36:324-330. https://doi.org/10.1016/S1701-2163(15)30608-3

22. Pross SE, Sharon JD, Lim M et al (2017) Spontaneous intracranial hypotension after vestibular schwannoma resection due to an unexpected pathology: Tarlov cysts. Cureus. https://doi. org/10.7759/cureus. 1261

23. Ramadorai UE, Hire JM, DeVine JG (2014) Magnetic resonance imaging of the cervical, thoracic, and lumbar spine in children: spinal incidental findings in pediatric patients. Glob Spine J 4:223-228. https://doi.org/10.1055/s-0034-1387179

24. Ramirez N, Flynn JM, Hill BW et al (2015) Evaluation of a systematic approach to pediatric back pain. J Pediatr Orthop 35:28 32. https://doi.org/10.1097/BPO.0000000000000190

25. Senoglu N, Senoglu M, Ozkan F et al (2013) The level of termination of the dural sac by MRI and its clinical relevance in caudal epidural block in adults. Surg Radiol Anat 35:579-584. https:// doi.org/10.1007/s00276-013-1108-2

26. Shi X, Zhu X, Zhao J (2003) The imaging analysis of magnetic resonance myelography in disease of the lumbosacral nerve roots. Chin J Clin Rehabil 7:320

27. Tani S, Hata Y, Tochigi S et al (2013) Prevalence of spinal meningeal cyst in the sacrum. Neurol Med Chir (Tokyo) 53:91-94. https ://doi.org/10.2176/nmc.53.91

28. Zacharakis D, Grigoriadis T, Bourgioti C et al (2018) Pre- and postoperative magnetic resonance imaging (MRI) findings in patients treated with laparoscopic sacrocolpopexy. Is it a safe procedure for all patients? Neurourol Urodyn 37:316-321. https ://doi.org/10.1002/nau.23294

29. Zeitoun R, Mohieddin MSA (2019) Coronal STIR sequence, a simple adjustment to routine MRI protocol for extra-spinal sciatica and sciatica-like symptoms. Egypt J Radiol Nucl Med. https ://doi.org/10.1186/s43055-019-0096-6

Publisher's Note Springer Nature remains neutral with regard to jurisdictional claims in published maps and institutional affiliations. 